\title{
HIPERINFECCIÓN POR STRONGYLOIDES STERCORALIS EN UN PACIENTE CON INFECCIÓN POR VIRUS HTVL-1
}

\author{
Sonia Saavedra ${ }^{1, a}$ William Lapa ${ }^{1, b}$, María Tenorio ${ }^{1, c}$, José Hernández ${ }^{1, c}$, Javier Uribe ${ }^{1, c}$.
}

1. Hospital Regional Docente de Ica, Perú.

a. Médico Gastroenteróloga b. Médico residente de Medicina Interna c. Médico Internista

\section{RESUMEN}

Strongyloides stercolaris en un nemátodo endémico en países de clima tropical y subtropical, la infección suele manifestarse por síntomas predominantemente digestivos, en los casos de hiperinfestación produce una strongiloidiasis diseminada con sobreinfecciones bacterianas sistémicas que provocan una disfunción multiorgánica. Los factores de riesgo más importantes para que una infección en principio intestinal adquiera características de gravedad son la inmunosupresión así como la infección por HTVL-1. Presentamos un caso de síndrome de hiperinfección por S. stercolaris en un paciente con HTLV-1. (Rev. méd. panacea 2011; 1:47-49).

Palabras clave: Infecciones por nematodos; Strongyloides stercolaris; Paciente inmunodeprimido; Infecciones por HTVL-1.

\section{HIPER-INFECTION BY STRONGYLOIDES STERCORALIS IN A PATIENT WITH HTLV-1 INFECTION}

\begin{abstract}
SUMMARY
Strongyloides stercolaris is an endemic nematode in tropical and subtropical climates. Infection is predominantly manifested by gastrointestinal symptoms, and in cases of hyper-infestation causes a disseminated strongyloidiasis with a systemic bacterial overinfection causing multiple organ dysfunctions with fatal outcome. The most important risk factors for intestinal infection to acquire gravity features include immunosuppression and HTVL-1 infection. The case presented corresponds to $S$. stercoralis hyperinfection syndrome in a patient with HTVL-1 infection. (Rev. méd. panacea 2011; 1: 47-49).
\end{abstract}

Key words: Nematode infections; Strongyloides stercolaris; inmunocompromise patient; HTVL-1 infection.

\section{INTRODUCCIÓN}

El síndrome de hiperinfección por Strongyloides stercoralis se refiere a la infección masiva diseminada, en la que el número de parásitos se incrementa de forma importante y las larvas son detectables en regiones extraintestinales como: corazón, cerebro, hígado y especialmente en los pulmones. Dado que algunos microorganismos intestinales pueden acompañar a las larvas en su migración, no son infrecuentes los cuadros de sepsis, meningitis y neumonía asociados ${ }^{(1,2)}$. Los factores de riesgo más importantes para que una infección, en principio intestinal $y$, en ocasiones asintomática, adquiera características de severidad, son la inmunosupresión, desnutrición grave, infección por $\mathrm{VIH}$, infección por HTVL-1; alcoholismo y la utilización de corticoides por su capacidad de alterar la función eosinofílica ${ }^{(3)}$. En eta oportunidad, presentamos el caso de un paciente con infección por HTVL-1 con síndrome de hiperinfección por S. stercoralis

\section{REPORTE DE CASO}

Paciente varón de 29 años procedente y residente en la ciudad de Pisco, departamento de Ica, Perú; de ocupación obrero (desagües). Como antecedentes destacan que desde hace cuatro años cursa con periodos de diarrea crónica, hace dos años fue hospitalizado en Pisco por: enfermedad diarreica crónica con baja de peso y bronquitis aguda, con hallazgo de $S$. stercoralis en heces por lo cual recibe tratamiento con albendazol. Además refiere el tener contacto sexual con múltiples parejas.

Ingresa al Servicio de Medicina del Hospital Regional de Ica, con un cuadro caracterizado por un tiempo de enfermedad de tres meses con deposiciones semilíquidas, dos a cuatro cámaras diarias asociadas a dolor abdominal difuso tipo cólico, de moderada intensidad; concomitantemente presenta episodios de deposiciones semilíquidas con rastros de sangre. Presenta también una marcada baja de peso en los dos últimos meses $(20 \mathrm{~kg})$. Hace un mes se adiciona tos con expectoración hemoptoica.

Hace una semana la tos se hace más exigente, con expectoración amarillenta y rastros de sangre; por otro lado aparecen vómitos biliosos. Hace cuatro días se asocia respiración rápida y marcado compromiso del estado 
general, motivo por el cual acude a emergencia del Hospital.

En la exploración realizada al ingreso, destacaba un enfermo caquéctico, en muy mal estado general, con Frecuencia respiratoria $28 \times$ min, TA 90/50, frecuencia cardiaca $94 \times$ min, temperatura axilar de $38,2{ }^{\circ} \mathrm{C}$. Piel con turgencia disminuida, mucosas secas, palidez de piel y mucosa. Tejido celular subcutáneo disminuido, edema en manos y pies. Tórax simétrico, retracciones intercostales, murmullo vesicular con pasaje rudo en ambos campos pulmonares, con crepitantes. Ruidos Cardiacos rítmicos, taquicardia, soplo sistólico multifocal. Abdomen distendido, no doloroso a la palpación profunda, ruidos hidroaéreos aumentados en frecuencia, matidez en hemiabdomen inferior con concavidad superior. El examen neurológico reveló: Glasgow: 13/15 (AO: 4 RV: 3 RM: 6), pupilas isocóricas, hiporeactivas, no presentaba signos de focalización ni signos meníngeos.

Los exámenes de laboratorio revelan: una anemia severa microcítica, hipocrómica, sin leucocitosis ni hipereosinofilia; con pruebas de función renal conservada. Un perfil hepático con hipoproteinemia e hipoalbuminemia marcadas. En el examen de esputo y heces se halla larvas de $S$. stercoralis. El estudio de líquido ascítico muestra ausencia de hipertensión portal, test de ADA dentro de límites normales, ecografía abdominal con ascitis moderada sin otros hallazgos.

El estudio de esputo y líquido ascíticos fueron negativos para bacilo de Koch (tres muestras), ELISA para VIH no reactivo, ELISA para HTVL-1 reactivo (dos veces). Radiografía de tórax con hallazgos de infiltración intersticial y alveolar parahiliar bilateral (Figura 1).

Con ello se concluyó en un cuadro de hiperinfección por Strongyloides stercoralis asociado a una coinfección por HTVL-1, neumonía bilateral con estado de insuficiencia respiratoria aguda y sepsis; desnutrición severa con ascitis de etiología carencial. Por lo que recibe tratamiento con ceftazidima, amikacina, ivermectina, transfusión de sangre total (tres unidades), fluidoterapia y oxigenoterapia.

El paciente presentó una evolución favorable después de nueve días de tratamiento, con mejoría del estado general y hemodinámico.

\section{DISCUSIÓN}

EI S. stercoralis es un parasito perteneciente al grupo de los nematodos, endémico en regiones rurales de países con clima tropical y subtropical en donde puede afectar entre 30 y 100 millones de personas ${ }^{(2)}$.

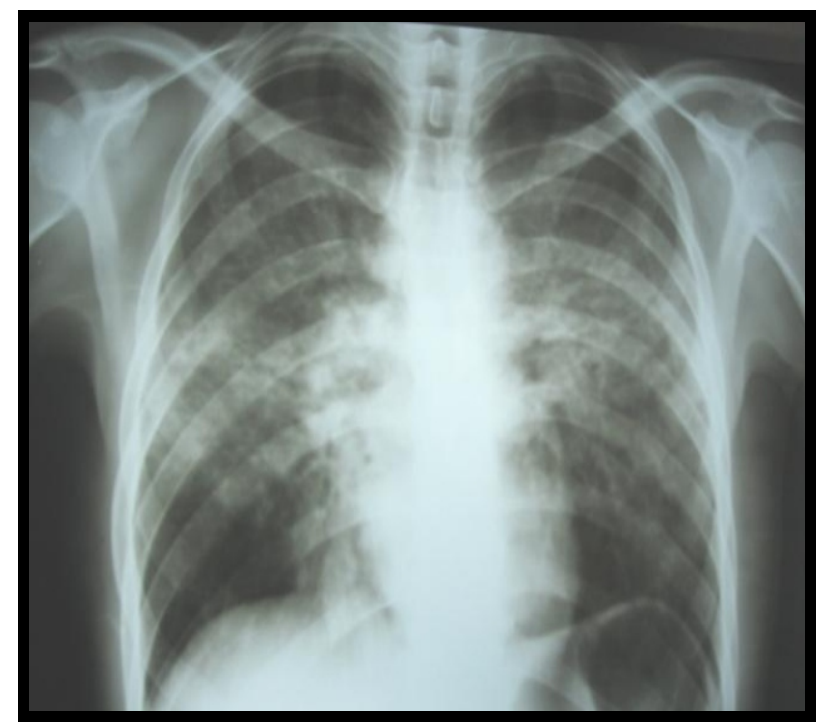

Figura 1. Radiografía de tórax donde se muestra infiltrado intersticial y alveolar bilateral.

La infección por Strongyloides stercoralis se adquiere por la penetración, a través de la piel, de las larvas filariformes presentes en el suelo o en el agua. Una vez en el interior del hospedero la corriente sanguínea lleva las larvas hasta los pulmones, donde atraviesan los capilares pulmonares y salen a los alveolos. Migran a la tráquea y faringe, se los deglute y al llegar al duodeno atraviesan la mucosa donde la hembra deposita los huevos que darán lugar a la eclosión de larvas (no infectivas), que llegan a la luz del intestino y se expulsan con las heces ${ }^{(3)}$.

En el síndrome de autoinfección, las larvas presentes en la luz intestinal pueden desarrollarse en larvas infectivas o filariformes mientras pasan a través del intestino, producen una reinfección en el propio hospedero y ocasionan una enfermedad crónica de larga duración. Esta infección crónica puede ser clínicamente inaparente o manifestarse por síntomas cutáneos, gastrointestinales o pulmonares, y puede con llevar el fenómeno denominado ,,,hiperinfección, con incremento notable de parásitos fuera del tracto digestivo. Este cuadro se ha descrito en casos de inmunosupresión relacionada con infección por HTVL-1 ${ }^{(4)}$.

El cuadro clínico respiratorio se produce por la infiltración larvaria de los espacios vasculares y alveolares, y da como resultado edema pulmonar, bronconeumonía y microhemorragias intraalveolares que, con un importante efecto acumulativo, producen neumonitis e insuficiencia respiratoria, que puede evolucionar a un síndrome de dificultad respiratoria aguda y falla multiorgánica. La mortalidad en estos pacientes alcanza cifras superiores al $80 \%$ 
El diagnóstico del síndrome de hiperinfección se realiza mediante la visualización de larvas de $S$. stercoralis en muestras principalmente del pulmón. En el hemograma cabría esperar eosinofilia, que orientaría hacia la sospecha de una infección por parásitos, pero cuando ya se ha desarrollado hiperinfección por $S$. stercoralis, no hay eosinofilia y el recuento de leucocitos suele ser variable ${ }^{(6)}$.

En los casos de hiperinfección por $S$. stercoralis es importante realizar un diagnóstico precoz para mejorar el pronóstico de estos pacientes. Se recomienda administrar Ivermectina en casos de hiperinfección por S. stercoralis, la administración debe ser diaria hasta la resolución de los síntomas y la negativización de las muestras biológicas (al menos durante dos semanas).

La Ivermectina es similar, estructuralmente, a los macrólidos pero sin actividad antibacteriana, con una absorción del $60 \%$ por vía oral. Tiene una importante fijación a proteínas y la neurotoxicidad es el efecto adverso más importante. Se ha descrito también la administración conjunta de Ivermectina y Tiabendazol en los pacientes con hiperinfección por S. stercoralis ${ }^{(7,8)}$.

En nuestro caso, ante la presencia de un estado de inmunosupresión por HTVL-1, se desarrollo un estado de infección crónica de más de cuatro años de evolución, con diarrea crónica, hasta el punto de desarrollar un síndrome de hiperinfección; con afección pulmonar e intestinal a la que se asoció una sobreinfección bacteriana pulmonar, con desarrollo de insuficiencia respiratoria aguda; gran compromiso del estado nutricional (hipoalbuminemia), con desarrollo de edema en calcetín y ascitis.

La infección por HTLV-1 es un factor de riesgo para la enfermedad diseminada por Strongiloidiasis al igual que otros estados de inmunosupresión. Los pacientes con infección por HTLV-1 tienen altos niveles de producción de Interferón Gamma, lo que disminuye la producción de IL-4, IL-5, IL-13 e lg E, las moléculas importantes en la defensa del hospedero contra Strongyloides. Las células $T$ reguladoras pueden desempeñar un papel en la susceptibilidad a hiperinfección por Strongyloides. Entre los pacientes con infección por HTLV-1 asociada a infección por Strongyloides, los recuentos de células $\mathrm{T}$ reguladoras se incrementan y se correlacionan con los bajos recuentos de eosinófilos circulantes y la reducción de la producción de IL-5 ${ }^{(9)}$

En nuestro paciente la vía de infección para HTLV-1 fue la sexual, puesto que se realizo ELISA HTVL-1 en la madre la cual resulto no reactiva; se debe considerar además la procedencia y el antecedente sexual de riesgo, el cual era positivo en nuestro paciente ${ }^{(10)}$.

\section{REFERENCIAS BIBLIOGRÁFICAS}

1. Chu E, Whitlock WL, Dietrich RA. Pulmonary hiperinfection síndrome with Strongyloides stercoralis. Chest 1990;97(6):1475-7.

2. Siddiqui AA, Genta RM, Berk SL. Strongyloidiasis. Chap 111 in Trop Infectious Diseases - Principles, Practices and Pathogens. Churchhill-Livingstone Elsevier, Philadelphia, 2006. p.1274.

3. Keiser PB, Nutman TB. Strongyloides stercoralis in the immunocompromised population. Clin Microbiol Rev. 2004;17(1): 208-17.

4. Gotuzzo E, Terashima A, Alvarez H, Tello R, Infante R, Watts DM, Freedman DO. Strongyloides stercoralis hyperinfection associated with human $\mathrm{T}$ cell lymphotropic virus type-1 infection in Peru. Am J Trop Med Hyg. 1999;60(1):146-9.

5. Newberry AM, Williams DN, Stauffer WM, et al. Strongyloides hyperinfection presenting as acute respiratory failure and gram-negative sepsis. Chest 2005; 128:3681.

6. Satoh M, Kiyuna S, Shiroma Y, Toma H, Kokaze A, Sato Y. Predictive markers for development of strongyloidiasis in patients infected with both Strongyloides stercoralis and HTLV-1. Clin Exp Immunol. 2003;133(3):391-6.

7. Pacanowski J, Santos MD, Roux A, LE Maignan C, Guillot J, Lavarde V, Cornet M. Subcutaneous ivermectin as a safe salvage therapy in Strongyloides stercoralis hyperinfection syndrome: a case report. Am J Trop Med Hyg. 2005;73(1):122-4.

8. Terashima A, Alvarez $\mathbf{H}$, Tello $\mathbf{R}$, Infante $\mathbf{R}$, Freedman DO, Gotuzzo E. Treatment failure in intestinal strongyloidiasis: an indicator of HTLV-I infection. Int J Infect Dis. 2002;6(1):28-30.

9. Neva FA, Filho JO, Gam AA, Thompson R, Freitas V, Melo A, Carvalho EM. Interferon-gamma and interleukin-4 responses in relation to serum IgE levels in persons infected with human $\mathrm{T}$ lymphotropic virus type I and Strongyloides stercoralis. J Infect Dis 1998;178(6):1856-9.

10. Garrido P, Anicama R, Gotuzo E, Watts D. HTLV-1 en población de alto riesgo sexual de Pisco, Ica, Perú. Rev Med Hered 1997; 8(3):104-07.

Correspondencia: Dra. Sonia Saavedra Escobar. Correo electrónico: soniasaavedra96@yahoo.com 